\title{
Profile and Precipitation Retrievals and Validation Based on Geostationary Sub-Millimeter Atmospheric Sounder
}

\author{
Jieying He, Shengwei Zhang, Hao Liu, Ying Zhang \\ Key Laboratory of Microwave Remote Sensing, National Space Science Center, Chinese Academy of Sciences, \\ Beijing, China \\ Email: hejieying@mirslab.cn
}

Received 4 May 2016; accepted 26 June 2016; published 29 June 2016

Copyright (C) 2016 by authors and Scientific Research Publishing Inc.

This work is licensed under the Creative Commons Attribution International License (CC BY).

http://creativecommons.org/licenses/by/4.0/

\section{(c) (i) Open Access}

\begin{abstract}
The key factors of temporal and spatial resolution for typhoon observation played an important role in the design of radiometer used for observing typhoon. The NCEP (National Centres for Environmental Prediction) operational global analysis data prepared operationally every six hours were used as the initial field for mesoscale weather research and forecasting model (WRF) and drove the model to output atmospheric parameters such as hydrometeor content, temperature and humidity profiles at different time, which were inputs for the Atmospheric Radiative Transfer Simulator (ARTS) to calculate brightness temperature observed from geostationary earth orbit at oxygen absorption and water absorption band. The atmospheric humidity and temperature profiles of typhoon domain were retrieved from geostationary sub-millimetre atmospheric sounder. The results show that the profile retrievals using BP-NN algorithm have a best agreement with those from radiosonde, which is less than $20 \%$ and $1 \mathrm{~K}$ of root mean square error, respectively. For precipitation rate retrievals, much better agreement with rain gauge and ECMWF datasets, the RMS is between 0.84 to $32.4 \mathrm{~mm} / \mathrm{h}$ for sea surface 0.89 and $36.13 \mathrm{~mm} / \mathrm{h}$ for land surface according to the classification by precipitation type.
\end{abstract}

\section{Keywords}

Atmospheric, Profile, Precipitation, Geostationary Sub-Millimetre Atmospheric Sounder, Neural Network

\section{Introduction}

The current polar-orbiting meteorological satellite observation system ensures that the observation period is six

How to cite this paper: He, J.Y., Zhang, S.W., Liu, H. and Zhang, Y. (2016) Profile and Precipitation Retrievals and Validation Based on Geostationary Sub-Millimeter Atmospheric Sounder. Atmospheric and Climate Sciences, 6, 415-424.

http://dx.doi.org/10.4236/acs.2016.63034 
hours, which is unable to monitor typhoon and other fast changing situations. Only instruments on geostationary or comparable platforms can view regional disaster at the 15-min interval that is necessary to monitor rapidly evolving typhoon or cyclone events. This paper discusses the abilities of passive microwave/ sub-millimeter sensor which is being developed by our institute to retrieve atmospheric temperature and humidity profiles. Furthermore, we also carry out the work of retrieving surface precipitation rates and hydrometeor water paths.

Geostationary atmospheric sounder based on interferometric technology is the newest field of microwave remote sensing. Equipped with a sub-millimeter atmospheric remote sensing instruments on the geostationary orbit, meteorological satellite platform will increase the frequency of observations, at the same time, improve the cloud detection capability [1]-[3].

\section{Instrument Description}

According to the atmospheric sounding theory and gasous absorption coefficients from 0 - $1000 \mathrm{GHz}$, the final frequencies are chosen to derive atmospheric temperature and humidity profiles for geostationary sub-millimeter sounder, which are list in Figure 1 and Table 1, Table 2 shows characteristics of ultimately selected frequencies and their applications.

Since atmospheric absorbing characteristics of water vapor and oxygen, using satellite-borne microwave radiometer to derive atmospheric temperature and humidity profiles is possible. According to the principle above,

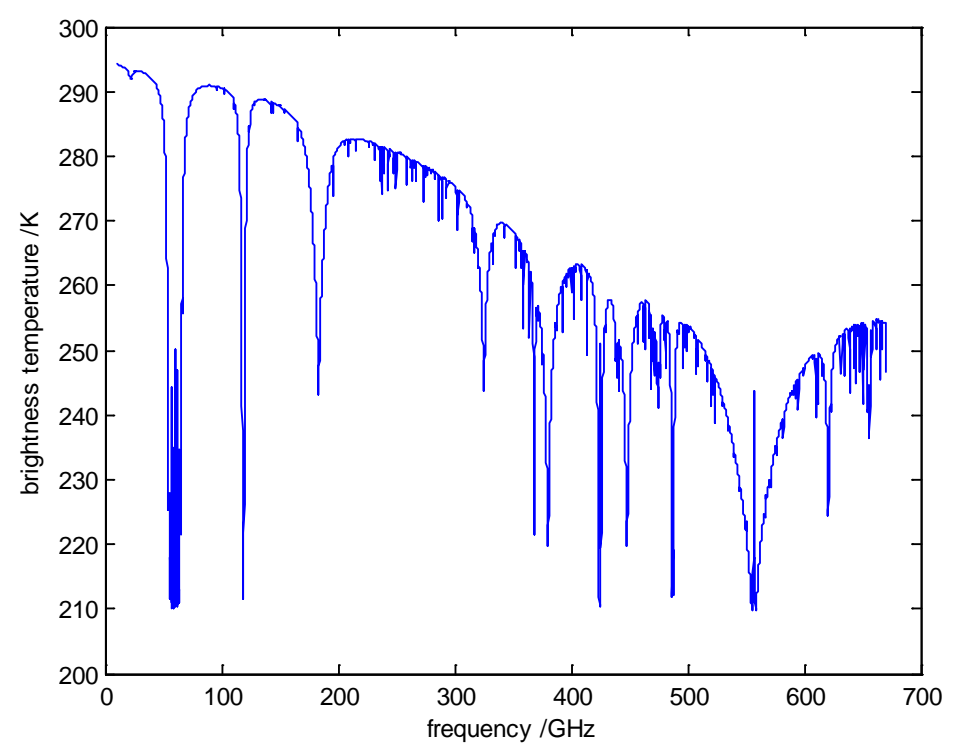

Figure 1. The standard atmospheric profiles.

Table 1. Candidate frequencies for geostationary sub-millimeter sounder.

\begin{tabular}{cccc}
\hline No. & Frequency $(\mathrm{GHz})$ & Characteristics & Applications \\
\hline 1 & $55-64$ & Oxygen & Temperature profiles \\
2 & 118.75 & Oxygen & Temperature profiles \\
3 & 150.0 & window & Surface information \\
4 & 183.31 & Water vapor & Humidity profiles \\
$\mathbf{5}$ & 220.0 & Window & Surface information \\
$\mathbf{6}$ & 380.19 & Water vapor & Humidity profiles \\
$\mathbf{7}$ & 424.76 & Oxygen & Temperature profiles \\
$\mathbf{8}$ & 556.93 & Water vapor & Humidity profiles \\
\hline
\end{tabular}


Table 2. Characteristics of ultimately selected frequencies.

\begin{tabular}{cccc}
\hline No. & Frequency $(\mathrm{GHz})$ & Characteristics & Applications \\
\hline 1 & 118.75 & Oxygen & Temperature profiles \\
2 & 183.31 & Oxygen & Humidity profiles \\
3 & 380.197 & Window & Humidity profiles \\
4 & 424.763 & Water vapor & Temperature profiles \\
\hline
\end{tabular}

when the radiometer operated at frequencies 50 - $1000 \mathrm{GHz}$, the contribution of surface background noise can be reduced to negligible magnitude, because the transmittance of the atmosphere at these frequencies is approximately equal to 0 .

Atmospheric opacity thickness with pressure integration can be expressed as:

$$
\tau(z)=\int_{0}^{z} \alpha\left(z^{\prime}\right) \mathrm{d} z^{\prime}
$$

where $\alpha(z)$ is atmospheric at altitude $z, z^{\prime}$ is height from surface to satellite.

For oxygen absorbing channels, $\tau(z)$ is basically due to the contribution of oxygen.

Equation (1) can be expressed as the weighted integral of temperature:

$$
T_{b}(v, \theta)=T_{u}(v, \theta)+\int_{0}^{\infty} W_{T}(v, \theta, z) T(z) \sec (\theta) \mathrm{d} z .
$$

The temperature weighing function can be expressed as:

$$
W_{T}(v, \theta, z)=\left[1+\left(1-e_{s}\right)\left(\frac{\Upsilon_{v \theta}(0, \infty)}{\Upsilon_{v \theta}(z, \infty)}\right)^{2}\right] \frac{\partial \Upsilon_{v \theta}(z, \infty)}{\partial z}
$$

where,

$$
\gamma_{v, \theta}(0, \infty)=\mathrm{e}^{-\tau(0) \sec (\theta)}
$$

Furthermore, water vapor weighing function can be expressed as:

$$
W_{\rho}(v, z)=W_{T}(v, z) \frac{T(z)}{\rho_{v}(z)} .
$$

Weighting function is the weight of atmospheric radiance at height $\mathrm{z}$ from surface to the height of the satellite. The plane parallel atmosphere was divided into $\mathrm{N}$ layers, the absorbing coefficient of atmospheric parameters was assumed uniform in each layer, and then attenuation contributions of entire atmosphere including the surface layer can be accumulated. Atmospheric absorbing coefficients in each channel can be calculated combining MPM93 [4] and PWR04 [5] model. Therefore, we can choose the central frequency and bandwidth for each channel of geostationary sub-millimeter atmospheric sounder according to the weighting functions, which is displayed in Figure 2.

\section{Data Processing}

\subsection{Simulation of Full-Disk Model of Earth}

Brightness temperatures are simulated by the validated global reference physical model, NCEP/WRF/ARTS, composed of the US National Center for Environment Prediction (NCEP) analyses, the new generation National Center for Atmospheric Research/Penn State Mesoscale Model (WRF) and the Atmospheric Radiative Transfer Simulator, ARTS, which is a software for performing simulations of atmospheric radiative transfer [6]-[9]. The output of WRF model consists of temperature and humidity profiles, pressure profiles, surface mask, and surface parameters and so on. 

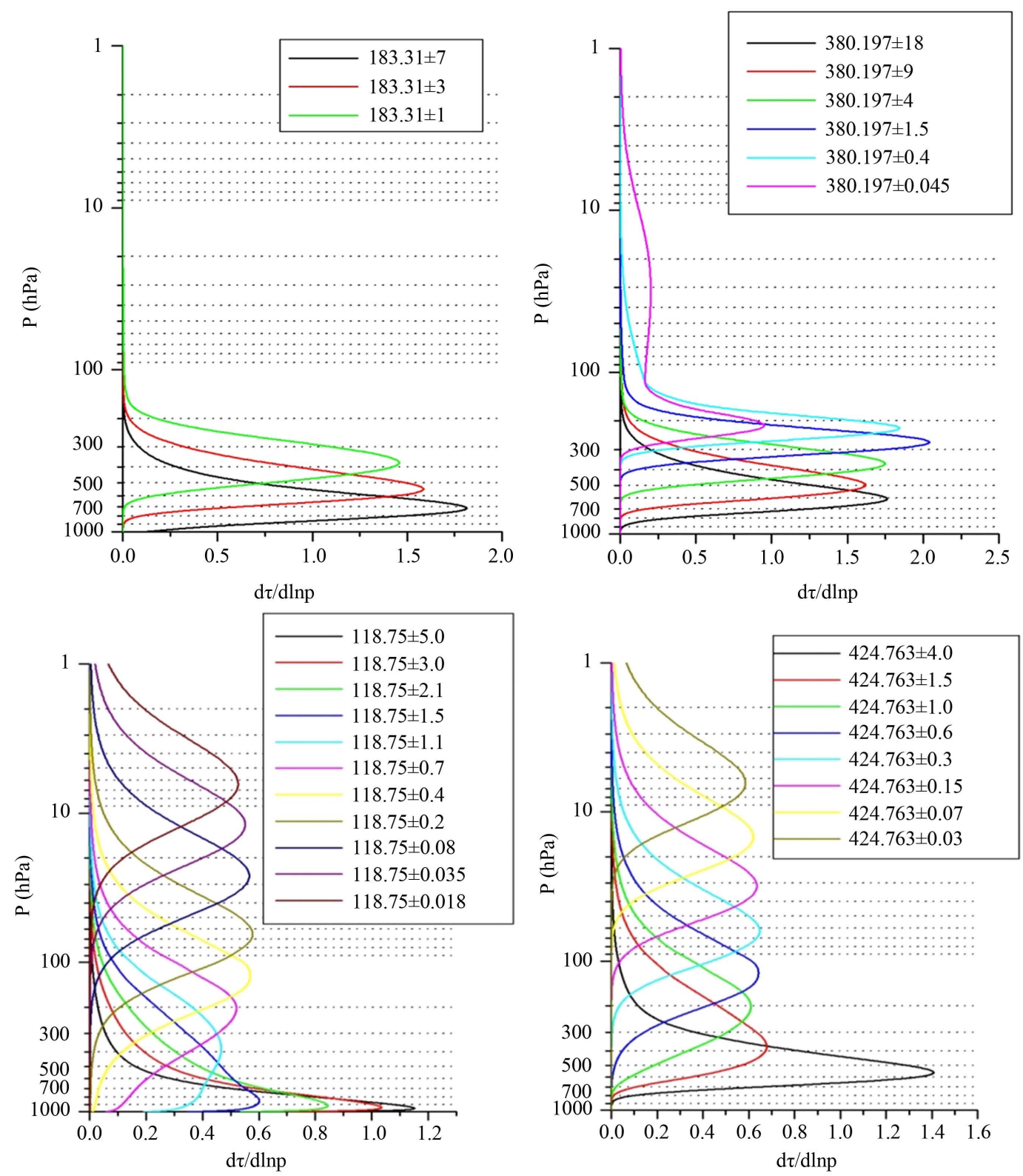

Figure 2. The standard atmospheric profiles.

By using the WRF (weather research and forecasting) model, the paper simulated the seasonal tropical cyclone activity over western North Pacific at $53.596 \mathrm{GHz}$ from 1 June to 30 September 2015, like Figure 3 shows. Therefore the results show that: 1) the simulated total number of Typhoons is close to that from Best-track dataset; 2) The simulated intensity of typhoons is comparable to that from Best-track data set, but the time limit needs further exploration.

\subsection{Observation from MWHTS}

Until now, no observation data from geostationary satellite can be used to realize the profile and precipitation rates retrievals. To solve this problem, this paper uses the observing data from microwave humidity and temperature sounder onboard FY-3C (FY-3C MWHTS) which plays an important role in monitoring extreme climate, especially for typhoon since September $30^{\text {th }}, 2013$, such as typhoon "kujira”, "Linfa”, "chan-hom" and "Nangka”, monitoring their procedure of generating, evolution, strengthen and die out (as showing in Figure 4 and 
J. Y. He et al.
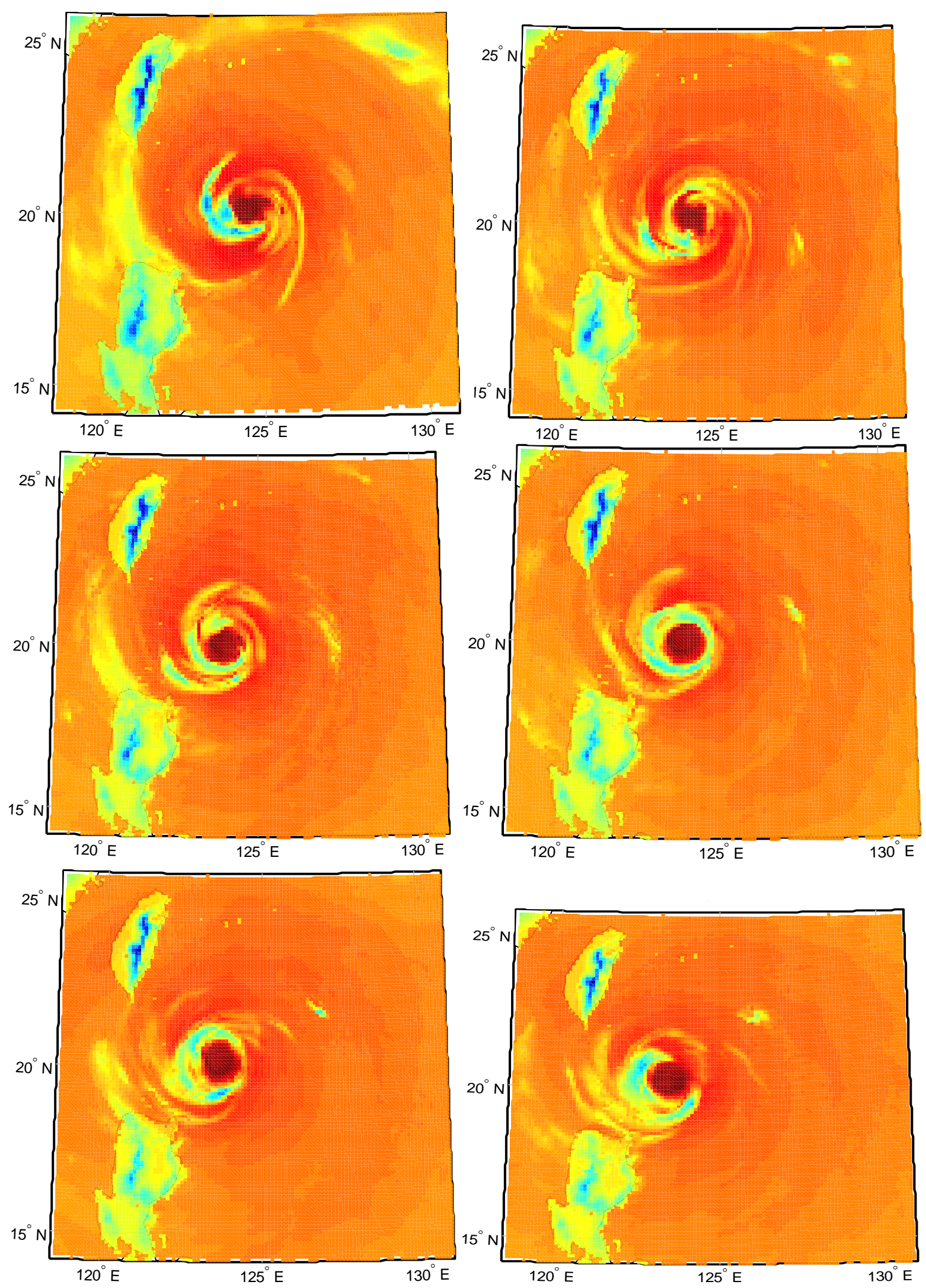

Figure 3. Brightness temperature simulation for typhoon evolution. Time: 8, 9, 10, 11, 12 and 13 o'clock. 


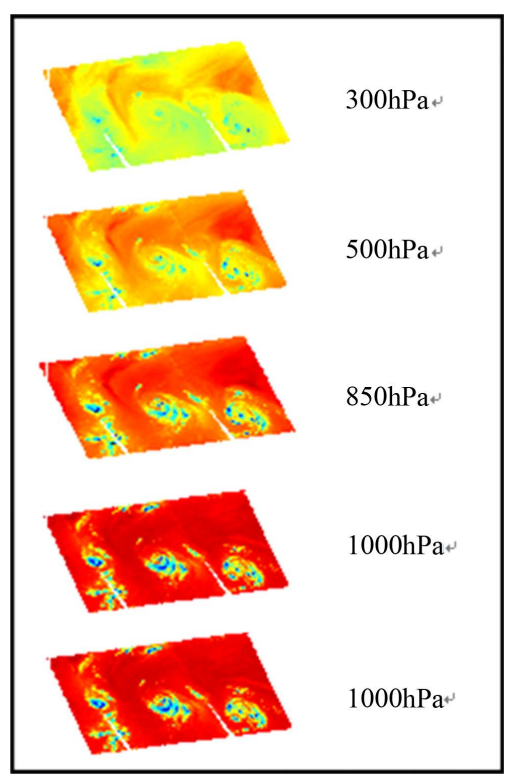

Figure 4. Brightness temperatures distribution at different pressure-level at $118 \mathrm{GHz}$.

Figure 5), especially locating the typhoon eye area clearly and intuitively with the resolution of 15 kilometers, and also predicting the heavy rainfall caused by typhoon for South China [10]-[12].

\section{Retrieval Algorithm}

ANN is essentially a nonlinear statistical regression between a set of predictors (in this case the observation vectors $\mathrm{X}$ ) and a set of predictands (in this case profiles of atmospheric temperature Z) [13]. The structure of the ANN is shown in Figure 6. In this paper, we construct a three layer ANN model. The layers 1, 2, and 3 represent the input layer, the hidden layer, and the output layer, respectively.

The neurons of the input layer are represented by vector $X_{\mathrm{i}}\left(X_{1}, X_{2}, X_{3}, \cdots, X_{L}\right)$, where $L$ is the number of the input neurons. The neurons of the middle layer are represented by vector $Y_{\mathrm{i}}\left(Y_{1}, Y_{2}, Y_{3}, \cdots, Y_{M}\right)$, where $M$ is the number of the hidden neurons. The neurons of the output layer are represented by vector $Z_{\mathrm{i}}\left(Z_{1}, Z_{2}, Z_{3}, \cdots, Z_{N}\right)$, where $N$ is the number of the output neurons.

The node in the hidden layer can be expressed as:

$$
Y_{j}=S\left(\sum_{i=1}^{L} w_{i j} x_{i}+b_{j}\right)
$$

where, $w_{i j}$ is the weighting of the connection between the $j^{\text {th }}$ hidden neuron and the $i^{\text {th }}$ input neuron and $b_{j}$ denotes the bias in the $j^{\text {th }}$ neuron of the hidden layer. The linear function is applied between the output layer and the hidden layer. Where, $\mathrm{S}$ denotes the sigmoid function:

$$
S(a)=\frac{1}{1+\exp (-a)}
$$

According to the characteristics of sigmoid function, the values of both input and output layers should be transformed to the range $[0,1]$. Outputs can be expressed as:

$$
Z_{k}=\sum_{j=1}^{M} w_{j k} Y_{j}+b_{k}
$$

where $w_{j k}$ is the weight of the connection between the $j^{\text {th }}$ hidden neuron and the $k^{\text {th }}$ output neuron; $b_{k}$ is the bias in the $k^{\text {th }}$ neuron of the output layer.

For geostationary sub-millimeter atmospheric sounder, several kinds of ANN are used according to the types of surface and sky, like land and sea, clear-sky, cloudy sky, rainy sky, typhoon-sky and so on. The schematic 
20150707 1458-2003

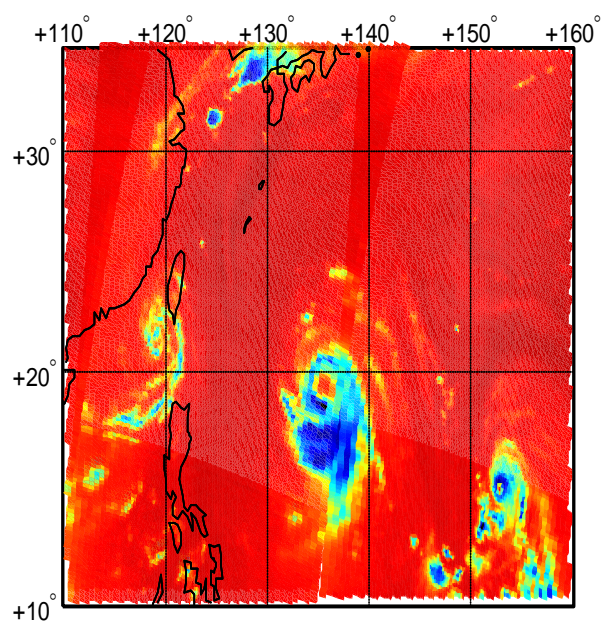

Figure 5. Brightness temperatures distribution when three typhoons happened at July $7^{\text {th }}$, 2015. Left to right: Typhoon "Linfa", "chan-hom" and "Nangka".

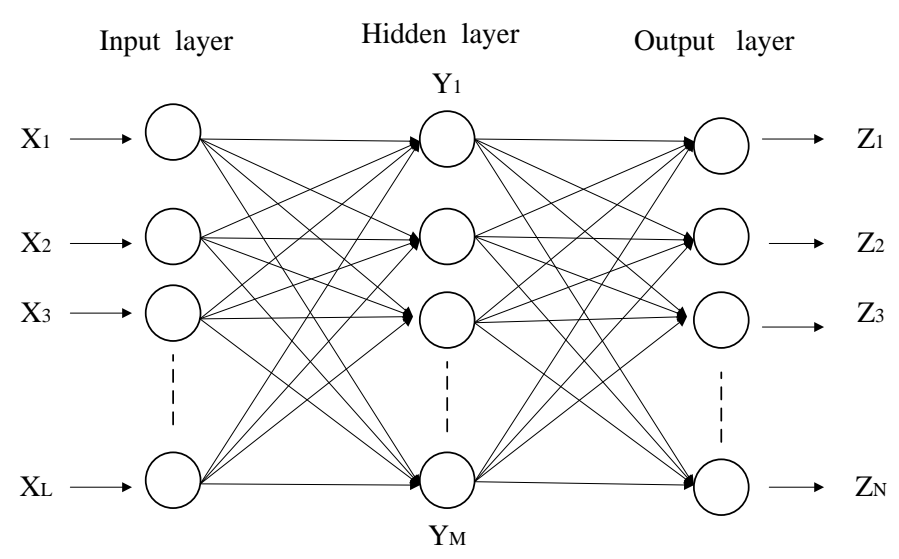

Figure 6. Schematic of retrieving flow.

algorithm is showed in Figure 7.

\section{Retrieval Results and Analysis}

Figure 8 shows the profile retrievals of temperature and humidity (T\&H) using simulated brightness temperatures from microwave radiometer onboard gestational platform, which also gives the root mean square error distribution, respectively.

For the temperature profile, when there is a thin inversion layer, large deviations occur from the neural network retrieval model. It is mainly because of its own shortcoming for nonlinear neural network. When the inversion layer is thick enough, the neural network inverse model can be well reflected for the details of atmospheric temperature changes. Water vapor varies significantly from time to time and from space to space. Certainly the fact is that water vapor is the source of all clouds and precipitation which would be enough to explain its retrieving difficulties. Therefore compared to temperature, water vapor and relative humidity profiles are retrieved with relatively larger difficulty with challenge. The retrievals show that the RMS of atmospheric temperature profile is less than $2.5 \mathrm{~K}$, RMS of atmospheric relative humidity profile is better than $20 \%$, which can be converted to atmospheric absolute humidity, and the RMS is less than $0.4 \mathrm{~g} / \mathrm{m}^{3}$ as shown in Figure 8 .

For precipitation the primary radiometric signal at frequencies around $183 \mathrm{GHz}$ from precipitating scenes results from the scattering by ice hydrometeors. This scattering can result in significant brightness temperature 

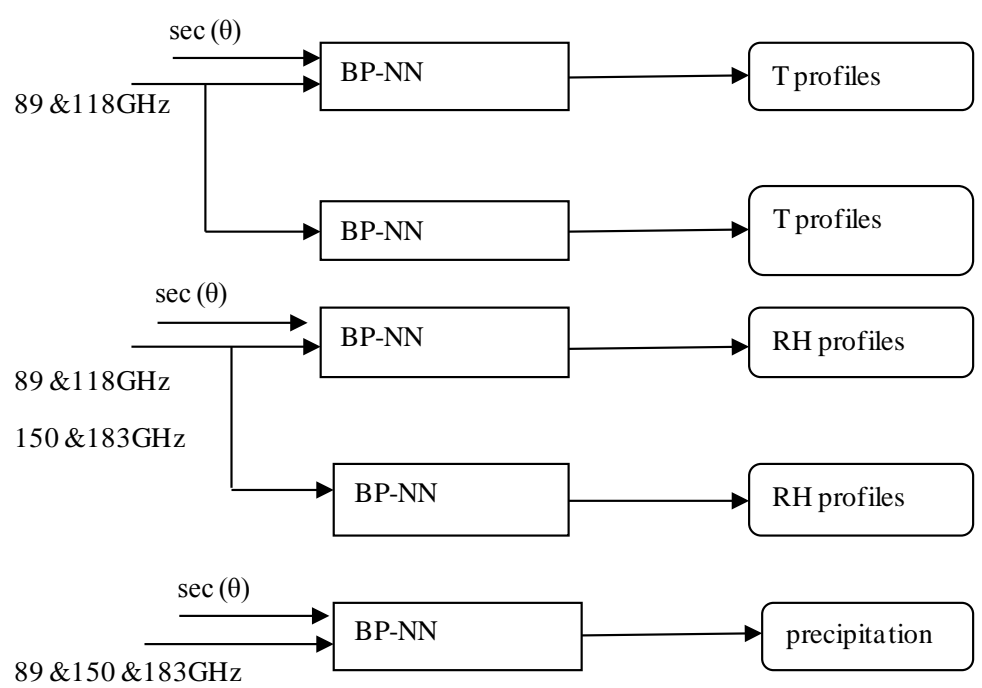

Figure 7. Schematic of retrieving flow.
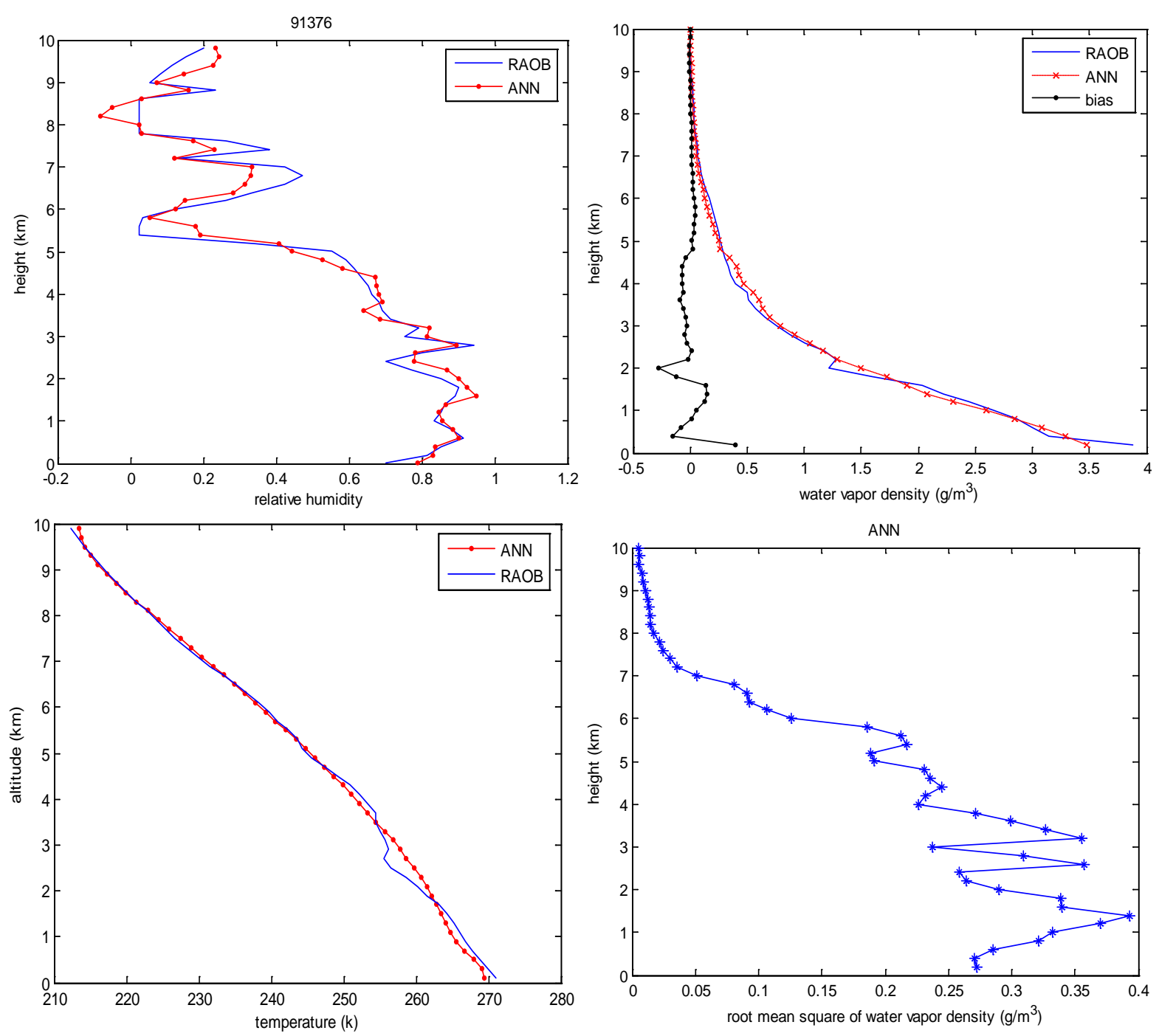

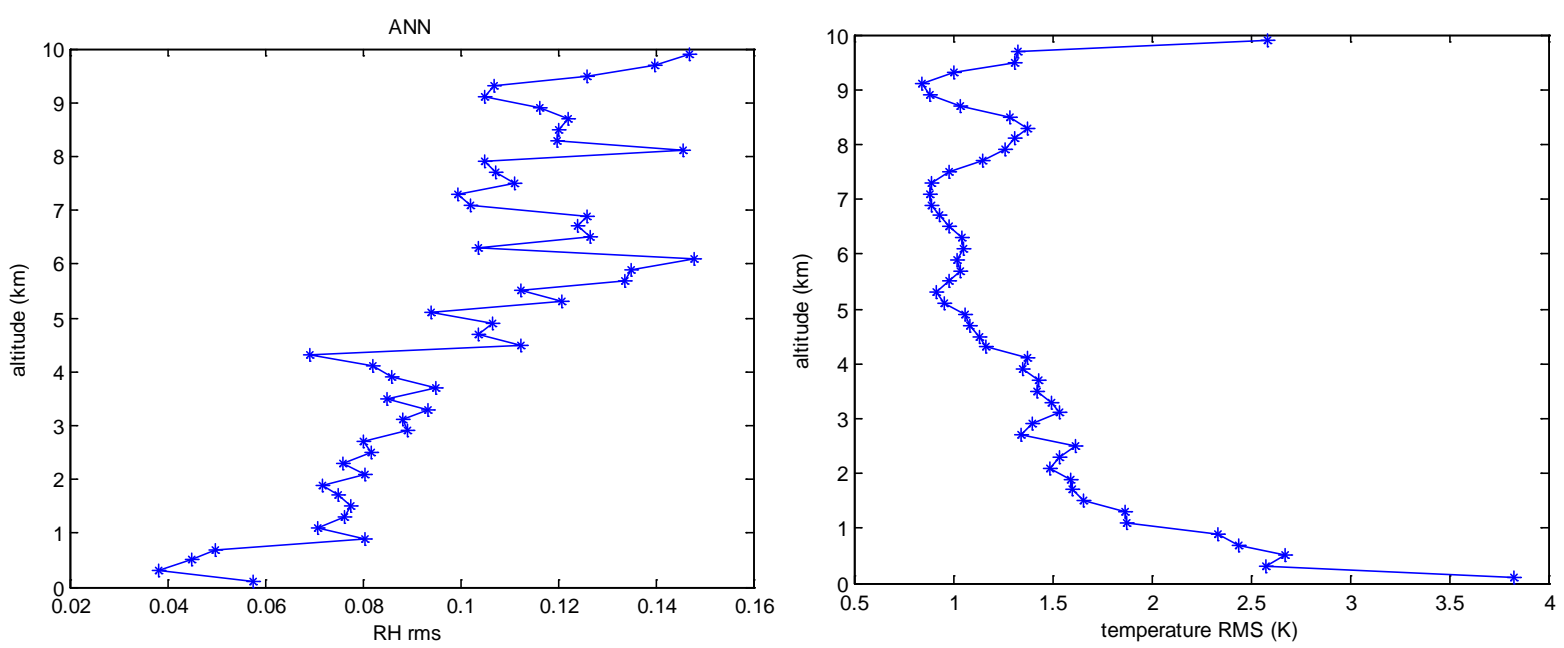

Figure 8. Profile retrievals of temperature and humidity (T\&H) using simulated brightness temperatures from microwave radiometer onboard gestational platform.
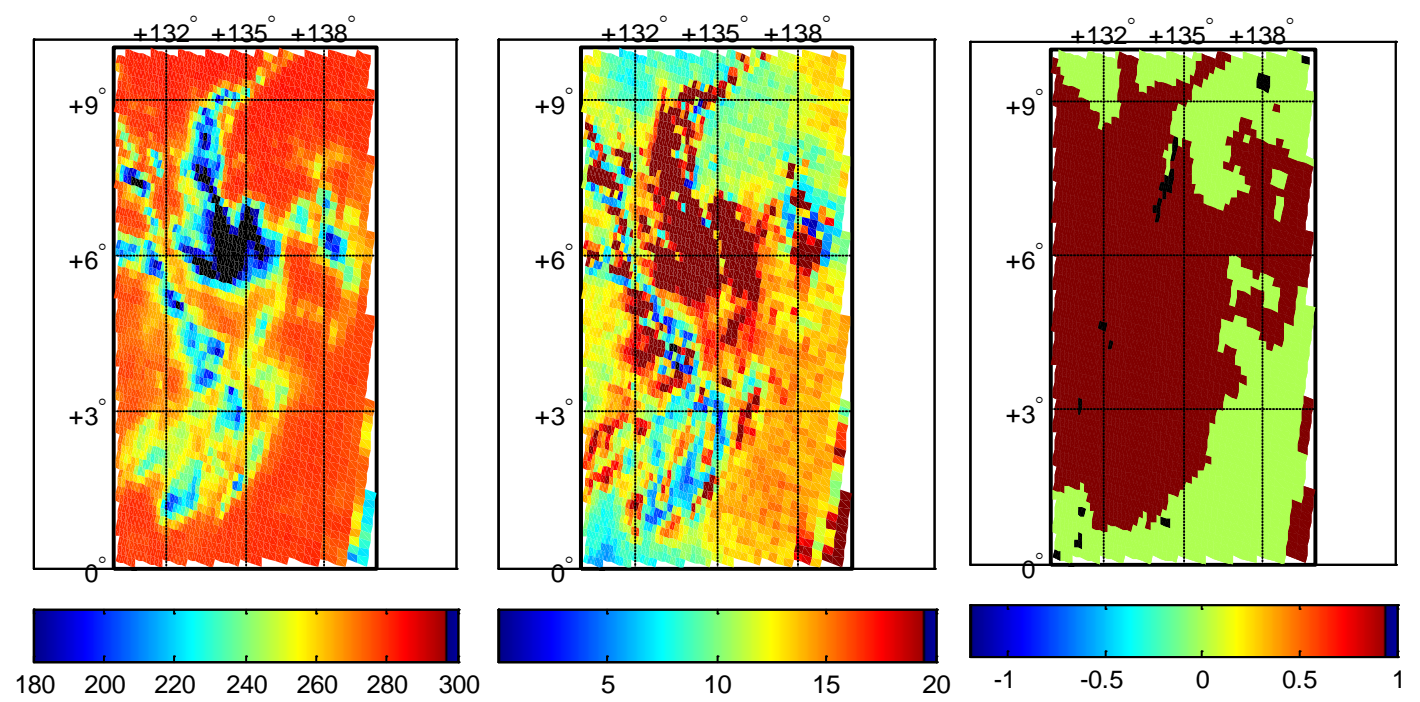

Figure 9. Rain detection according to the brightness temperature analysis.

depressions (several 10's K) relative to non-precipitating surroundings, and is therefore a sensitive proxy for the presence of precipitation at the surface.

According to the global difference distributions of brightness temperatures on Jan 20, 2015, a) channel 10 plus channel 15, b) for channel 10 plus channel 9, and c) for channel 9 plus channel 15 for FY-3C MWHTS, using neural network method, the precipitation and rain detection can be derived, which is shown in Figure 9 and Table 3.

\section{Summary and Conclusions}

According to the retrievals and analysis, geostationary sub-millimeter atmospheric sounder will play an important role in studying global climate and is the main remote sensing instrument for meteorology and disaster. It works in all weather and all day providing the observation of brightness temperature which can be used to retrieve temperature and humidity profiles and precipitation rate.

There is a well agreement in temperature and humidity profiles between radiosonde and retrievals. Compared to radiosonde, the retrievals show that the RMS of atmospheric temperature profile is less than $1 \mathrm{~K}$, RMS of atmospheric relative humidity profile is less than $20 \%$, which can be converted to atmospheric absolute humidity, 
Table 3. Rain detection of typhoon domain by geostationary sub-millimeter atmospheric sounder between Jan. 1 to Oct. 31, 2014.

\begin{tabular}{cccc}
\hline Location & Rain rate $(\mathrm{mm} / \mathrm{h})$ & Land $\mathrm{rms} / \mathrm{K}$ & Sea rms/K \\
\hline $0.1-1$ & 0.89 & 0.84 \\
$1-5$ & 4.03 & 3.54 \\
Typhoon domain & $5-10$ & 7.45 & 6.78 \\
& $10-30$ & 20.21 & 17.21 \\
& $30-50$ & 23.28 & 21.23 \\
$50-65$ & 36.13 & 32.4 \\
\hline
\end{tabular}

and the RMS is less than $0.4 \mathrm{~g} / \mathrm{m}^{3}$.

For the recent work, the surface is classified the surface mark as land, sea and coastal, using the observing data to detect weather it is rain or not and then test and validate the accuracy of the rain rate. Therefore, the work provides algorithms and data analysis of temperature and humidity profiles and precipitation distribution. So, the work will play an important role in the design and development of following meteorological satellites.

Because it is not enough, the authors are doing further improvement, like considering the surface covered by snow, ice and rainforest. Also, the rain rate is excepted to be retrieved more accurately. The radar data are also needed to validate the accuracy of rain detection. All of above will be described in future paper.

\section{References}

[1] Gomas, B.B. (2005) Geostationary Observatory for Microwave Atmospheric Sounding. Submitted to ESA in Response to the Call for Ideas for the Next Earth Explorer Core Missions.

[2] Liu, H., Wu, J., Zhang, S.W., et al. (2011) The Geostationary Interferometric Microwave Sounder (GIMS): Instrument Overview and Recent Progress. IEEE International Geoscience and Remote Sensing Symposium, Vancouver, 24-29 July 2011, 3629-3632.

[3] Zhang, C., Liu, H., Wu, J., et al. (2015) Imaging Analysis and First Results of the Geostationary Interferometric Microwave Sounder Demonstrator. IEEE Transactions on Geoscience And Remote Sensing, 53, 3629-3632.

[4] Liebe, H.J. (1989) MPM-An Atmospheric Millimeter-Wave Propagation Model. International Journal of Infrared and Millimeter Waves, 10, 631-650. http://dx.doi.org/10.1007/BF01009565

[5] Rosenkeanz, P.W. (2001) Retrieval of Temperature and Moisture Profiles from AMSU-A and AMSU-B Measurements. IEEE Transactions on Geosciences and Remote Sensing, 39, 2429-2435.

[6] Chen, S.H. and Dudhia, J. Annual Report: WRF PHYSICS [R/OL]. http://www2.mmm.ucar.edu/wrf/users/docs/wrf-doc-physics.pdf

[7] http://www.ecmwf.int/en/about/media-centre/news/2014/ecmwf-starts-using-chinese-satellite-data

[8] NCEP Global Tropospheric Analyses, $1 \times 1$ Daily Sep. 15, 1999-Present [Online]. http://rda.ucar.edu/datasets/ds083.2/\#!access

[9] Davis, C., Emde, C. and Harwood. R. (2005) A 3D Polarized Reversed Monte Carlo Radiative Transfer Model for mm and Sub-mm Passive Remote Sensing in Cloudy Atmospheres. Transactions on Geophysicas and Remote Sensing, 43, 1-6.

[10] Zhang, S.W., Li, J., Jiang, J., Zhang, Y., Wang, Z. and Dong, X. (2006) Microwave Humidity Sounder (MWHS) of Chinese Meteorological Satellite FY-3. Proceedings of the Microwave Technology and Techniques Workshop_Enabling Future Space Systems, ESA/ESTEC, Noordwijk, The Netherlands, May 15-16, 2006, ESA SP-632.

[11] Zhang, S.W., Li, J. and Wang, Z.Z. (2012) Design of the Second Generation Microwave Humidity Sounder (MWHS-II) for Chinese Meteorological Satellite FY-3. 2012 IEEE International Geosciences and Remote Sensing Symposium (IGARSS), Munich, 22-27 July 2012, 4672-4675.

[12] He, J.Y., Zhang, S.W. and Wang, Z.Z. (2015) Advanced Microwave Atmospheric Sounder (AMAS) Channel Specifications and T/V Calibration Results on FY-3C Satellite. Transactions on Geophysicas and Remote Sensing, 53, No. 1.

[13] He, J.Y., Zhang, S.W. and Wang, Z.Z. (2012) The Retrievals and Analysis of Water Vapor Density in Arctic Regions Using FY-3A Satellite MWHS. Radio Science, 47, 301-311. 


\section{Submit or recommend next manuscript to SCIRP and we will provide best service for you:}

Accepting pre-submission inquiries through Email, Facebook, Linkedin, Twitter, etc A wide selection of journals (inclusive of 9 subjects, more than 200 journals)

Providing a 24-hour high-quality service

User-friendly online submission system

Fair and swift peer-review system

Efficient typesetting and proofreading procedure

Display of the result of downloads and visits, as well as the number of cited articles

Maximum dissemination of your research work

Submit your manuscript at: http://papersubmission.scirp.org/ 